\title{
Synthesis and Structure Analysis of Ferrocene-Containing Pseudopeptides
}

\section{Gaetano Angelici a ${ }^{*}$, Marcin Górecki a,b, Gennaro Pescitelli a, Nicola Zanna c, Magda Monari c, Claudia Tomasini ${ }^{c *}$}

a Dipartimento di Chimica e Chimica Industriale - Università di Pisa - Via Moruzzi 13 - 56124 Pisa Italy

${ }^{\mathrm{b}}$ Institute of Organic Chemistry - Polish Academy of Sciences - ul. Kasprzaka 44/52, 01-224 - Warsaw - Poland

" Dipartimento di Chimica "Giacomo Ciamician", Università di Bologna - Via Selmi, 2 - 40126 Bologna - Italy

\begin{abstract}
Ferrocene with its aromaticity and facile redox properties is an attractive moiety to be incorporated into functional moieties. Medicinal applications of ferrocene are well known and ferrocene itself shows cytotoxic and antianemic properties. In this paper, we will describe the synthesis and the structure analysis of two pseudopeptides containing a ferrocene moiety as N-terminal group. After purification, Fc-L-Phe-D-Oxd-OBn [L-Phe = L-phenylalanine; D-Oxd = (4R,5S)-4-Methyl-5-carboxyoxazolidin-2-one] appears as bright brown solid that spontaneously forms brown needles. The X-ray diffraction of the crystals shows the presence of strong $\pi$ interactions between the ferrocenyl moiety and the phenyl rings, while no $\mathrm{N}-\mathrm{H} \bullet \bullet \mathrm{O}=\mathrm{C}$ hydrogen bonds are formed. This result is confirmed by FT-IR and ${ }^{1} \mathrm{H}$ NMR analysis. In contrast, both FT-IR and ${ }^{1} \mathrm{H}$ NMR analysis suggest that Fc-(L-Phe-D-Oxd) ${ }_{2}-\mathrm{OBn}$ forms a turn conformation stabilized by intramolecular $\mathrm{N}-\mathrm{H} \bullet \bullet \mathrm{O}=\mathrm{C}$ hydrogen bonds in solution. Chiroptical spectroscopies (ECD and VCD) substantially confirmed the absence of a well-defined folded structure. The presence of the Fc moiety is responsible for specific ECD signals, one of which displayed a pronounced temperature dependence and is directly related with the helicity assumed by the Fc core. Solid-state ECD spectra were recorded and rationalized on the basis of the X-ray geometry and quantum-mechanical calculations.
\end{abstract}

\section{Introduction}


Ferrocene $(\mathrm{Fc})$ with its aromaticity and facile redox properties is an attractive moiety to be incorporated into functional molecules. Since its discovery in 1951,[1] ferrocene and its derivatives have attracted the attention of many researchers in the field of organometallic chemistry because of their fascinating sandwich structure.[2]

In last few decades, interest in ferrocene derivatives has grown, $[3,4]$ together with their applications as biosensors,[5-7] magnetic and stimuli responsive materials,[8,9] redox active polymer.[10] Ferrocene derivatives have been also used in nonlinear optics,[11] organic synthesis,[12,13] asymmetric catalysis,[14] bio-organometallic and biological chemistry,[15] and medicine.[16,17] Ferrocenyl-based peptides have great importance in biological as well as non-biological systems.[18,19] They are classified based on number of amino acid conjugates attached to ferrocenyl group and are termed mono-, di-, and tri-peptides. Among them, the behavior of ferrocene-phenylalanine-phenylalanine (Fc-FF) has been studied in details.[20,21] Wang and Qi et al. reported that Fc-FF changed the conformation of the secondary structures from the flat $\beta$-sheets conformation of phenylalanine-phenylalanine (FF) into twisted $\beta$-sheets, and the detailed diameters of the twists can be controlled by counterions, temperature and solvents.[13,22,23] Recently, Domingos et al.[24] have described the use of Fc as redox-switchable probe of local peptide structure based on vibrational circular dichroism. This latter report exemplifies the use of X-ray diffraction, IR, NMR and chiroptical spectroscopies to characterize Fc-containing pseudopeptides. In this work, we report the synthesis and the conformational study of two pseudopeptides capped with a ferrocene group. We demonstrate that the ferrocene moiety prevents the formation of folded conformations, in contrast with the behaviour of similar pseudopeptides capped with the Boc (tert-butyloxycarbonyl) group.

\section{Materials and Methods}

Materials - All chemicals and solvents were purchased by Sigma-Aldrich, VWR or Iris Biotech and used as received. Acetonitrile was distilled under inert atmosphere before use. Solvent were dried by distillation before use. All reactions were carried out in dried glassware. The melting points of the compounds are uncorrected. High quality infrared spectra (64 scans) were obtained with an ATR-FT-IR Bruker Alpha System spectrometer (64 scans). The spectra were obtained in $3 \mathrm{mM}$ solutions in dichloromethane or as solids at $297 \mathrm{~K}$. All compounds were dried in vacuo and all the sample preparations were performed in a nitrogen atmosphere. NMR spectra were recorded with a Varian Inova 400 spectrometer at $400 \mathrm{MHz}\left({ }^{1} \mathrm{H} \mathrm{NMR}\right)$ and $100 \mathrm{MHz}\left({ }^{13} \mathrm{C} \mathrm{NMR}\right)$. Chemical shifts are 
reported in $\delta$ values relative to the solvent peak. Compounds Boc-L-Phe-D-Oxd-OBn and Boc-(L-PheD-Oxd) $2-\mathrm{OBn}$ were prepared by following the procedure reported in literature.[25,26] ECD spectra were measured with a Jasco J-715 spectropolarimeter with the following conditions: scan speed 100 $\mathrm{nm} / \mathrm{min}$; response $0.5 \mathrm{~s}$; data pitch $0.2 \mathrm{~nm}$; bandwidth $1.0 \mathrm{~nm} ; 4$ accumulations. Variabletemperature ECD spectra were run with a home-made Peltier apparatus designed cylindrical cells, equipped with an Ascon MS 30 controller ( $\pm 1^{\circ} \mathrm{C}$ accuracy). ECD solid state spectrum was recorded as a $\mathrm{KCl}$ pellet using the protocol developed previously.[27] VCD and IR spectra were recorded using a Jasco FVS-6000 VCD spectrometer with the following conditions: resolution $4 \mathrm{~cm}^{-1}$; range 2000$900 \mathrm{~cm}^{-1} ; 4000$ accumulations.

Fc-L-Phe-D-Oxd-OBn - Trifluoroacetic acid (486 $\mu \mathrm{L}, 6.3 \mathrm{mmol})$ was added under nitrogen atmosphere to a solution of Boc-L-Phe-D-Oxd-OBn (169 mg, $0.35 \mathrm{mmol}$ ) in dry dichloromethane (5 $\mathrm{mL}$ ). After 4 hours the reaction was complete, dichloromethane was removed under reduced pressure and $\mathrm{H}$-L-Phe-D-Oxd-OBn$\cdot \mathrm{CF}_{3} \mathrm{CO}_{2} \mathrm{H}$ was obtained in quantitative yield. To a stirred solution of $\mathrm{H}$-L-Phe-D-Oxd-OBn. $\mathrm{CF}_{3} \mathrm{CO}_{2} \mathrm{H}(134 \mathrm{mg}, 0.35 \mathrm{mmol})$ and $\mathrm{HBTU}(148 \mathrm{mg}, 0.39 \mathrm{mmol})$ dissolved in dry acetonitrile $(15 \mathrm{~mL})$, under inert atmosphere, ferrocenecarboxylic acid ( $80 \mathrm{mg}, 0.35 \mathrm{mmol}$ ) dissolved in dry acetonitrile $(10 \mathrm{~mL})$ was added at room temperature, together with a solution of DIEA (180 $\mu \mathrm{L}, 1.1 \mathrm{mmol})$. The reaction was monitored by thin layer chromatography; when the reaction is complete acetonitrile was removed under reduced pressure. Then the crude mixture was dissolved in dichloromethane $(30 \mathrm{~mL})$ and washed with brine $(30 \mathrm{~mL}), 1 \mathrm{~N}$ aqueous $\mathrm{HCl}(30 \mathrm{~mL}), 5 \%$ aqueous $\mathrm{NaHCO}_{3}(30 \mathrm{~mL})$ and brine $(30 \mathrm{~mL})$, dried over sodium sulphate and concentrated in vacuo. The product (145 mg, 70\% yield) was obtained pure after silica gel chromatography (DCM, then $2 \%$ AcOEt in DCM).

M.p. $=173.1-174.1^{\circ} \mathrm{C}$; IR ( $3 \mathrm{mM}$ in $\mathrm{CH}_{2} \mathrm{Cl}_{2}$ ): v 3435, 1792, 1754, 1710, 1663, $1508 \mathrm{~cm}^{-1}$; IR (ATR-IR): v 3404, 1799, 1748, 1721, 1646, $1528 \mathrm{~cm}^{-1} ;{ }^{1} \mathrm{H}$ NMR (400 MHz, $\mathrm{CDCl}_{3}$ ): $\delta 1.46$ (s, 3H, $\mathrm{CH}_{3}$ Oxd), 3.03 (s, 1H, $\left.\mathrm{CH}_{2} \beta-\mathrm{Phe}\right), 3.23$ (s, 1H, $\left.\mathrm{CH}_{2} \beta-\mathrm{Phe}\right), 4.07-4.65$ (m, 9H, CH Cp), $4.68-4.96(\mathrm{~m}, 2 \mathrm{H}, \mathrm{CHN}-\mathrm{Oxd}+$

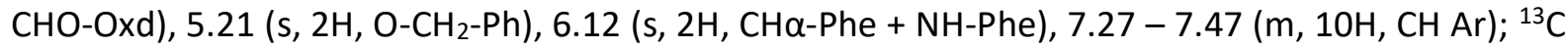
NMR $\left(100 \mathrm{MHz}, \mathrm{CDCl}_{3}\right) \delta$ 21.3, 38.5, 52.7, 62.1, 68.2, 68.7, 70.0, 70.7, 73.8, 76.8, 77.2, 77.5, 127.4, $128.6,128.8,128.8,129.5,134.7,136.0,151.3,167.4,169.7,172.7$. Anal. Calcd. for $\mathrm{C}_{32} \mathrm{H}_{30} \mathrm{FeN}_{2} \mathrm{O}_{6}$ : C, 64.66; H, 5.09; N, 4.71. Found: C, 64.71; H, 5.05; N, 4.73. 
Fc-(L-Phe-D-Oxd) ${ }_{2}-\mathrm{OBn}$ - Trifluoroacetic acid $(494 \mu \mathrm{L}, 6.4 \mathrm{mmol})$ was added under nitrogen atmosphere to a solution of Boc-(L-Phe-D-Oxd) 2 -OBn $(269 \mathrm{mg}, 0.35 \mathrm{mmol})$ in dry dichloromethane $(5 \mathrm{~mL})$. After 4 hours the reaction was complete, dichloromethane was removed under reduced pressure and $\mathrm{H}-(\mathrm{L}-\mathrm{Phe}-\mathrm{D}-\mathrm{Oxd})_{2}-\mathrm{OBn} \cdot \mathrm{CF}_{3} \mathrm{CO}_{2} \mathrm{H}$ was obtained in quantitative yield. To a stirred solution of $\mathrm{H}-(\mathrm{L}-\mathrm{Phe}-\mathrm{D}-\mathrm{Oxd})_{2}-\mathrm{OBn} \cdot \mathrm{CF}_{3} \mathrm{CO}_{2} \mathrm{H}(233 \mathrm{mg}, 0.35 \mathrm{mmol})$ and $\mathrm{HBTU}(148 \mathrm{mg}, 0.39 \mathrm{mmol})$ dissolved in dry acetonitrile $(15 \mathrm{~mL})$, under inert atmosphere, ferrocenecarboxylic acid ( $80 \mathrm{mg}, 0.35$ $\mathrm{mmol})$ dissolved in dry acetonitrile $(10 \mathrm{~mL})$ was added at room temperature, together with a solution of $N, N$-diisopropylethylamine $(180 \mu \mathrm{L}, 1.1 \mathrm{mmol})$. The reaction was monitored by thin layer chromatography; when the reaction is complete acetonitrile was removed under reduced pressure. Then the crude mixture was dissolved in dichloromethane $(30 \mathrm{~mL})$ and washed with brine $(30 \mathrm{~mL})$, $1 \mathrm{~N}$ aqueous $\mathrm{HCl}(30 \mathrm{~mL}), 5 \%$ aqueous $\mathrm{NaHCO}_{3}(30 \mathrm{~mL})$ and brine $(30 \mathrm{~mL})$, dried over sodium sulphate and concentrated in vacuo. The product ( $190 \mathrm{mg}, 60 \%$ yield) was obtained pure after silica gel chromatography (DCM, then $4 \%$ AcOEt in DCM).

M.p. $=176.2-176.7^{\circ} \mathrm{C} ; \mathrm{IR}\left(3 \mathrm{mM}\right.$ in $\left.\mathrm{CH}_{2} \mathrm{Cl}_{2}\right): v 3435,3327,1790,1755,1717,1678,1646,1510 \mathrm{~cm}^{-1}$; IR (ATR-IR): v 3347, 1771, 1748, 1724, 1669, 1639, $1529 \mathrm{~cm}^{-1} ;{ }^{1} \mathrm{H}$ NMR $\left(400 \mathrm{MHz}, \mathrm{CDCl}_{3}\right): \delta 1.28$ (s, $3 \mathrm{H}, \mathrm{CH}_{3} \mathrm{Oxd}$ ), 1.39 (s, 3H, $\mathrm{CH}_{3} \mathrm{Oxd}$ ), $2.93-3.44$ (m, 4H, $\left.\mathrm{CH}_{2} \beta-\mathrm{Phe}\right), 3.90-4.81$ (m, 13H, $2 \mathrm{CHN}-\mathrm{Oxd}$

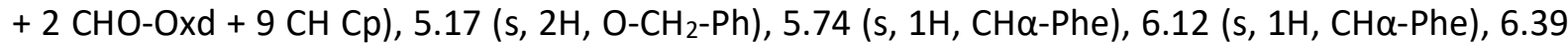
(s, 1H, NH-Phe), 7.25 - 7.48 (m, 10H), 7.94 (s, 1H, NH-Phe); ${ }^{13} \mathrm{C} \mathrm{NMR} \mathrm{(100} \mathrm{MHz,} \mathrm{CDCl}_{3}$ ): $\delta$ 14.2, 21.0, 21.1, 21.2, 29.7, 36.2, 37.9, 38.3, 52.6, 52.9, 53.6, 54.0, 60.4, 60.5, 61.8, 62.0, 62.7, 67.8, 67.9, 68.1, $68.4,69.0,70.2,71.3,73.4,73.9,74.2,75.3,75.6,76.8,77.2,77.4,77.5,127.0,127.3,127.5,128.2$, $128.4,128.4,128.6,128.7,128.7,128.8,128.8,129.0,129.3,129.4,129.7,134.7,134.8,135.9$, $135.9,136.1,151.1,151.3,152.0,167.0,167.5,169.6,171.5,171.6,172.7$. Anal. Calcd. for $\mathrm{C}_{46} \mathrm{H}_{44} \mathrm{FeN}_{4} \mathrm{O}_{10}: \mathrm{C}, 63.60 ; \mathrm{H}, 5.11 ; \mathrm{N}, 6.45$. Found: $\mathrm{C}, 63.63 ; \mathrm{H}, 5.14 ; \mathrm{N}, 6.43$.

\section{Crystallographic data collection and structure determination}

The X-ray intensity data of compound $\mathbf{1}$ was collected on a Bruker Apexll diffractometer equipped with CCD detector using Mo-Ka radiation. Cell dimensions and the orientation matrix were initially determined from a least-squares refinement on reflections measured in three sets of 20 exposures, collected in three different $\omega$ regions, and eventually refined against all data. A full sphere of reciprocal space was scanned by $0.3^{\circ} \omega$ steps. The software SMART [28] was used for collecting frames of data, indexing reflections and determination of lattice parameters. The collected frames were then processed for integration by the SAINT program,[28] and an empirical absorption 
correction was applied using SADABS. [29] The structures were solved by direct methods (SIR 97)[30] and subsequent Fourier syntheses and refined by full-matrix least-squares on $F^{2}$ (SHELXTL)[31] using anisotropic thermal parameters for all non-hydrogen atoms. The aromatic, methyl, methylene and methine hydrogen atoms were placed in calculated positions and refined with isotropic thermal parameters $U(H)=1.2 \operatorname{Ueq}(\mathrm{C})$ or $U(H)=1.5 \operatorname{Ueq}(\mathrm{C})$ (methyl $\mathrm{H}$ ), respectively and allowed to ride on their carrier carbons whereas the amidic $\mathrm{H}$ atom was located in the Fourier map and refined isotropically $\left[U(H)=1.2 U_{\text {eq }}(\mathrm{N})\right]$. Crystal data and details of the data collection for compound 1 are reported in Table S1.

CCDC-1564992 contains the supplementary crystallographic data for this paper. These data can be obtained free of charge at www.ccdc.cam.ac.uk/conts/retrieving.html (or from the Cambridge Crystallographic Data Centre, 12 Union Road, Cambridge CB2 1EZ, UK; Fax: +44-1223-336-033; email: deposit@ccdc.cam.ac.uk).

Computational Section - All calculations were run with Gaussian16 (Revision A.03. Wallingford, CT; 2016) with default grids and convergence criteria. The X-ray geometry of 1 was used as input structure; hydrogen atoms were optimized with DFT method at B3LYP/6-31G(d), while all nonhydrogen atoms were kept fixed. Excited-state calculations were run with TDDFT method at M06/TZVP level including 40 roots. A second functional (CAM-B3LYP) was also tested leading to consistent results. Transition density plots were generated with the program Multiwfn (v. 3.3.8),[32] using an isovalue of 0.0004. Calculated ECD spectra were generated with the program SpecDis v.1.71.[33]

\section{Results and Discussion}

In this paper, we will describe the synthesis and the conformational analysis of two pseudopeptides Fc-L-Phe-D-Oxd-OBn 1 and Fc-(L-Phe-D-Oxd)2-OBn 2 [L-Phe = L-phenylalanine; D-Oxd = (4R,5S)-4Methyl-5-carboxy-oxazolidin-2-one], that contain the ferrocene moiety as the $\mathrm{N}$-terminal group and we will demonstrate that the presence of the ferrocene unit strongly affects their preferred conformations (Figure 1). The two pseudopeptides are oligomers containing the L-Phe-D-Oxd unit, that is a privileged scaffold for the formation of supramolecular materials.[26,34-36] D-Oxd mimics a proline group and may form oligomers having stable secondary structures in solution, due to its ability to block the peptide bond always in the trans conformation.[37-39] 
<smiles>CC1OC(=O)N(C(=O)C(Cc2ccccc2)NC(=O)C2CC3C=CC2C3)C1C(=O)OCc1ccccc1</smiles>

FC-L-Phe-D-Oxd-OBn 1

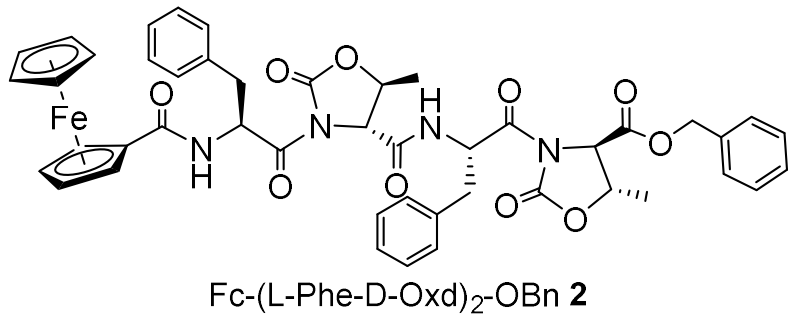

Figure 1. Chemical structure of pseudopeptides $\mathbf{1}$ and $\mathbf{2}$ described in this work.

We prepared Fc-L-Phe-D-Oxd-OBn 1 and Fc-(L-Phe-D-Oxd)2-OBn 2 by replacement of the Boc moiety with a ferrocene group in the already described Boc-L-Phe-D-Oxd-OBn [26] and Boc-(L-Phe-D-Oxd) $2_{2}$ OBn.[34] In both cases the Boc group was removed by reaction with trifluoracetic acid in dry dichloromethane followed by the formation of the amide by reaction with ferrocenecarboxylic acid in dry acetonitrile in the presence of HBTU [(2-(1H-benzotriazol-1-yl)-1,1,3,3-tetramethyluronium hexafluorophosphate] and DIEA ( $N, N$-diisopropylethylamine) (see Experimental and Supporting Information for details). Both compounds have been obtained pure as solid with a yield of $70 \%$ and $60 \%$ respectively.

After purification, Fc-L-Phe-D-Oxd-OBn 1 appears as bright brown solid that spontaneously forms brown needles during flash chromatography (solvent: cyclohexane and ethyl acetate in 1:1 ratio). The OM and SEM images of these crystals are reported in Figure 2.
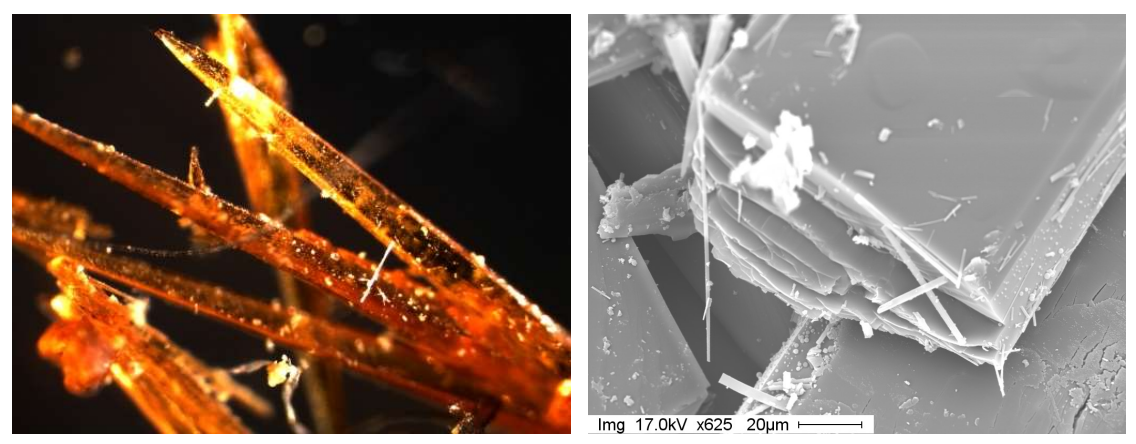

Figure 2. OM and SEM images of a sample of 1, crystallized from a 1:1 mixture of cyclohexane and ethyl acetate. 
One of these crystals has been investigated by single crystal X-ray diffraction and the molecular structure of 1 is shown in Figure 3. The most important torsion angles are reported in Table 1. Interestingly there is a strong intramolecular $\mathrm{C}-\mathrm{H}$... $\pi$ interaction between one $\mathrm{H}$ atom of the unsubstituted $\mathrm{Cp}$ ring of the ferrocenyl moiety and the terminal phenyl ring $[\mathrm{C}-\mathrm{H}$...Cg(C14-C19) 3.24 $\AA ̊]$.

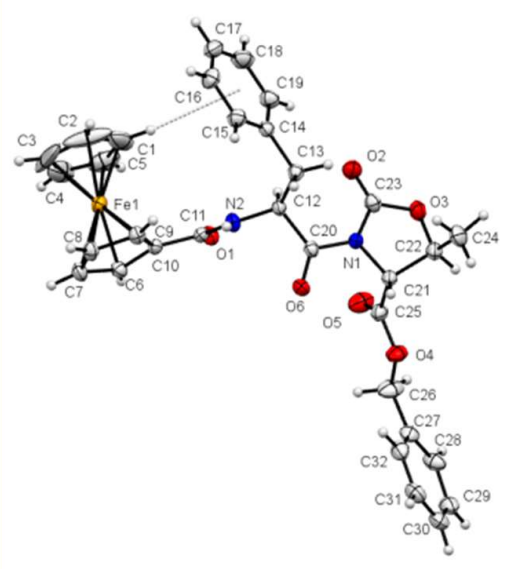

Figure 3. Molecular structure of $\mathbf{1}$. Dotted lines indicate an intramolecular $\mathrm{C}-\mathrm{H} \bullet \bullet \bullet \pi$ interaction. Thermal ellipsoids are drawn at $30 \%$ probability level.

Table 1. Selected backbone torsion angles $\left({ }^{\circ}\right)$ for 1.

\begin{tabular}{|c|c|c|c|}
\hline N1-C21-C25-O4(D-Oxd) & $-155.5(3)(\Psi 1)$ & N2-C12-C20-N1(L-Phe) & $172.8(3)(42)$ \\
\hline C25-C21-N1-C & $76.2(4)$ & C11-N2-C12-C20 & $-88.6(4) \quad(\phi 2)$ \\
\hline
\end{tabular}

The crystal packing, shown in Figure 4, is characterized by the presence of stacks of 1 running parallel to the $a$ axis. These stacks are formed by bifurcated non classical C-H $\bullet \bullet O$ hydrogen bonds (Figure S1) $\left[\mathrm{C} 15 \bullet \bullet \bullet \mathrm{O} 12.403(4) \AA, \mathrm{C} 15-\mathrm{H} 15 \bullet \bullet \bullet O 1153^{\circ}, \mathrm{C} 9 \ldots \mathrm{O} 13.731(4) \AA, \mathrm{C} 9-\mathrm{H} 9 \bullet \bullet \bullet \mathrm{O} 1155^{\circ}\right.$. 


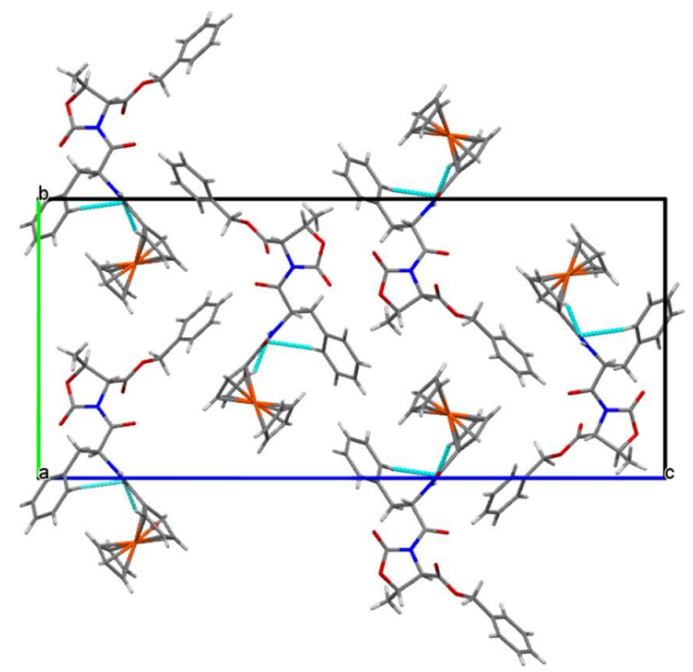

Figure 4. Crystal packing of Fc-L-Phe-D-Oxd-OBn 1. View down the $a$ axis. The light-blue lines indicate non-classical C-H...O hydrogen bonding.

In this case no $\mathrm{N}-\mathrm{H} \bullet \bullet \bullet \mathrm{O}=\mathrm{C}$ hydrogen bonds are formed, in contrast with what observed for FcFF. [22] Moreover the crystal packing of $\mathbf{1}$ is completely different from that we observed for Boc-LPhe-D-Oxd-OBn,[26] that forms a $\beta$-sheet conformation stabilized only by single hydrogen bonds. Also, the dimer Boc-(L-Phe-D-Oxd) $)_{2}-\mathrm{OBn}$ formed a fiber-like material with an anti-parallel $\beta$-sheet structure where the oligopeptide units were connected by one intermolecular hydrogen bond.[34] Much to our surprise, Fc-(L-Phe-D-Oxd) $)_{2}-\mathrm{OBn} 2$ do not form good crystals for X-ray diffraction analysis. The crystal formation was tried by evaporation of several solutions of $\mathbf{2}$ in pure solvent (chloroform, dichloromethane, methanol, ethyl acetate, acetonitrile, etc.) or solvent mixtures but any attempt failed.

To understand the reason for the different tendency to form crystals of the two pseudopeptides, we analyzed their preferred conformation in solution. To check the presence of intramolecular N$\mathrm{H} \bullet \bullet \mathrm{O}=\mathrm{C}$ hydrogen bonds, IR and ${ }^{1} \mathrm{H}$ NMR spectra were recorded in the structure supporting solvents $\mathrm{CH}_{2} \mathrm{Cl}_{2}$ and $\mathrm{CDCl}_{3}$, respectively.[40,41]

The analysis of the $\mathrm{N}-\mathrm{H}$ stretching regions in IR spectra enables to detect if intramolecular $\mathrm{N}$ $\mathrm{H} \bullet \bullet \mathrm{O}=\mathrm{C}$ hydrogen bonds are formed, because non-hydrogen-bonded amide $\mathrm{NH}$ groups exhibit a stretching signal above $3400 \mathrm{~cm}^{-1}$, while hydrogen-bonded amide $\mathrm{NH}$ ones produce a stretching band below $3400 \mathrm{~cm}^{-1}$. Both pseudopeptides feature free $\mathrm{N}-\mathrm{H}$ amide groups whose stretching band occurs at $3435 \mathrm{~cm}^{-1}$. However, when moving from 1 to $\mathbf{2}$, an intramolecular $\mathrm{N}-\mathrm{H} \bullet \bullet \bullet \mathrm{O}=\mathrm{C}$ hydrogen bond increases as a new broad band centered at about $3327 \mathrm{~cm}^{-1}$ appears (Figure 5). The same 
effect may be observed in the stretching bands relative to the amide $\mathrm{C}=\mathrm{O}$ group, that is located at $1663 \mathrm{~cm}^{-1}$ for 1 , while a new band located at $1640 \mathrm{~cm}^{-1}$ is recorded for 2 . The IR spectroscopy analysis confirms that 1 does not form in solution any intramolecular hydrogen bond, as previously observed in the crystal structure. In contrast, the IR spectra suggest that $\mathbf{2}$ forms an intramolecular $\mathbf{N}$ $\mathrm{H} \bullet \bullet \bullet \mathrm{O}=\mathrm{C}$ hydrogen bond, that probably involves the $\mathrm{NH}$ of the $\mathrm{C}$-terminal alanine unit.

The analysis of the spectra of solid $\mathbf{1}$ and $\mathbf{2}$, recorded with the ATR-IR technique, shows that even in the solid state 1 does not form a stable $\mathrm{N}-\mathrm{H} \bullet \bullet \bullet \mathrm{O}=\mathrm{C}$ hydrogen bond, as only a stretching band at $3404 \mathrm{~cm}^{-1}$ is recorded (Figure 5b). This outcome is perfectly in agreement with the result obtained with the X-ray diffraction analysis. In contrast, the ATR-IR spectrum of $\mathbf{2}$ shows the presence of a broad band centered at $3347 \mathrm{~cm}^{-1}$, typical of hydrogen bonded NH hydrogens. This finding suggests that a folded conformation is favoured in the case of the foldamer $\mathbf{2}$, whereas it does not take place in the foldamer $\mathbf{1}$, that folds in a fully extended conformation both in solution and in the solid state.
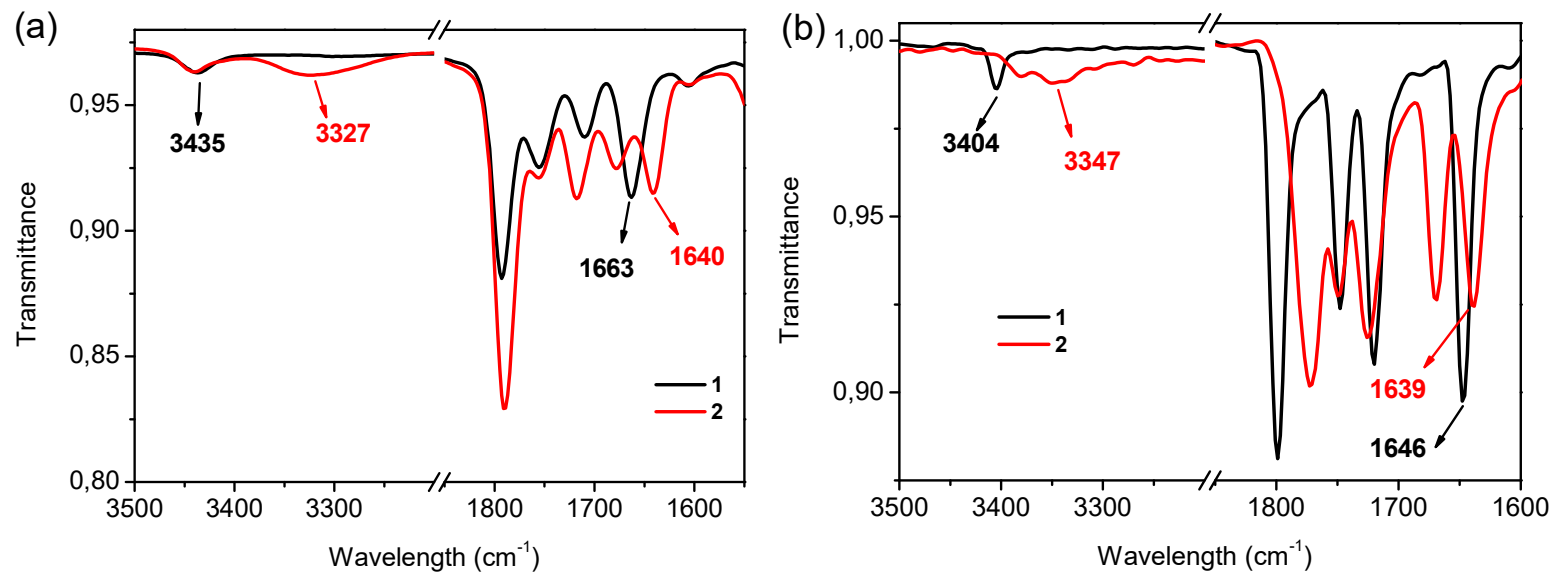

Figure 5. Selected regions of IR spectra of pseudopeptides 1 and 2: (a) IR spectra of $3 \mathrm{mM}$ solutions in dichloromethane; (b) ATR-IR spectra of solid pseudopeptides.

The occurrence of intramolecular $\mathrm{N}-\mathrm{H} \bullet \bullet \bullet \mathrm{O}=\mathrm{C}$ hydrogen bonds in compounds $\mathbf{1}$ and $\mathbf{2}$ has been further detected by an investigation of the DMSO- $d_{6}$ dependence of $\mathrm{NH}$ proton chemical shifts.[42,43] This solvent is a strong hydrogen-bonding acceptor and, if it is bound to a free $\mathrm{NH}$ proton, it will be expected to dramatically move its chemical shift downfield. The results for the DMSO, $d_{6} / \mathrm{CDCl}_{3}$ titrations of the $\mathrm{NH}$ protons for compound $\mathbf{2}$ is reported in Figure 6 . Unfortunately, the poor resolution of the ${ }^{1} \mathrm{H}$ NMR spectra of diluted solution of 1 inhibited to obtain clear and reproducible results for the titration of the NH group of 1. 


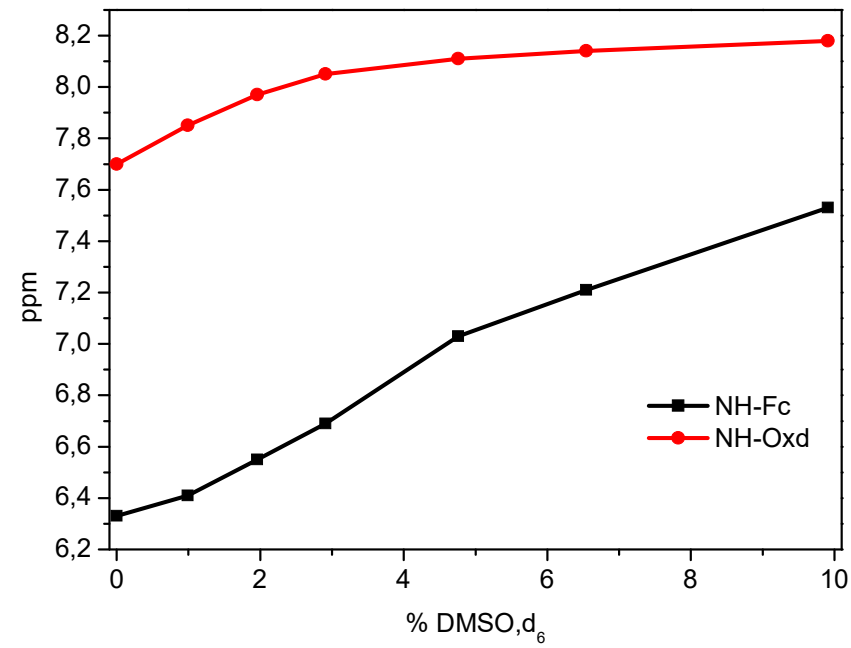

Figure 6. Variation of $\mathrm{NH}$ proton chemical shifts $(\mathrm{ppm})$ of $\mathbf{2}$ as a function of increasing percentages of DMSO$d_{6}$ added to the $\mathrm{CDCl}_{3}$ solution (v/v) (concentration $3 \mathrm{mM}$ ).

The outcome of this titration is in good agreement with the results obtained using FT-IR absorption, as one NH shows a chemical shift variation of about $1.2 \mathrm{ppm}$, which is a high $\Delta \delta$ value typical of nonhydrogen-bonded $\mathrm{NH}$ amide proton, while the other $\mathrm{NH}$ signal has a $\Delta \delta$ value of about $0.48 \mathrm{ppm}$ that agrees with hydrogen-bonded $\mathrm{NH}$ amide proton.

Unfortunately, the ROESY experiments, performed on $10 \mathrm{mM}$ solutions of $\mathbf{2}$ in $\mathrm{CDCl}_{3}$ furnished inconclusive results, due to the poor resolution typical of ferrocenyl containing molecules.

Additional characterization of $\mathbf{1}$ and $\mathbf{2}$ was carried out by electronic and vibrational circular dichroism (ECD and VCD).[44] ECD in particular has been thoroughly employed to study Fc-peptide conjugates, including Fc-FF.[45-55] VCD, apart from sensing peptide conformation,[56]-[57] may benefit from the presence of the Fc moiety as mentioned in the introduction.

The ECD spectra of $\mathbf{1}$ and $\mathbf{2}$ have been measured in acetonitrile at room temperature. The plots (Figure 7a) are the combination of several spectra measured with different cell path lengths, to cover the whole UV-vis range appropriately. In the near-UV/visible region, the ECD spectra display two bands for both 1 and 2 centered around 340 and $460 \mathrm{~nm}$ which are typical of Fc-containing peptides.

The sign of the band at $460 \mathrm{~nm}$ indicates the preferential helicity adopted by the Fc moiety, which is normally controlled by one or more intramolecular hydrogen bonds (as it occurs in 1,1'disubstituted Fc). ${ }^{37-47}$ In our case, the X-ray structure of 1 (Figures 3 and 4) features a $H \cdots \pi$ interaction between one cyclopentadienyl $(C p)$ and the adjacent Phe ring which may be responsible for the chirality transfer to the Fc. 

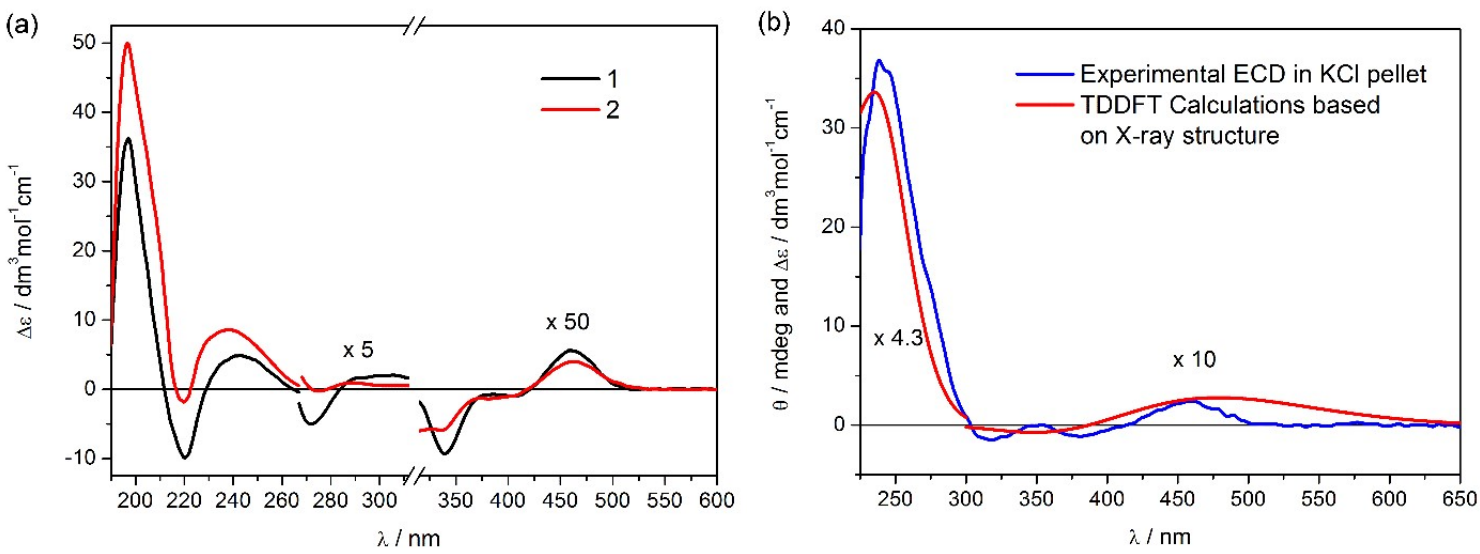

Figure 7. (a) ECD spectra of $\mathbf{1}$ and $\mathbf{2}$ in acetonitrile solution. (b) ECD spectrum of $\mathbf{1}$ in solid state superimposed with the calculated ECD spectrum based on X-Ray structure with TDDFT method at M06/TZVP level.

For a deeper insight, we report the ECD spectrum of 1 measured in the solid state as microcrystalline sample (Figure 7b). This latter technique reveals primarily the specific chiroptical response of the conformation found in the crystals (although it is also sensitive to intercrystalline interactions).[58] The consistency of the visible ECD band of $\mathbf{1}$ in solution and in the solid state demonstrates that the Fc helicity is preserved - at least in part - in solution.

In the UV region of the ECD spectra of $\mathbf{1}$ and $\mathbf{2}$, multiple bands of alternating sign are detected. This is not a surprising result, as the peptides UV/ECD spectra are notoriously sensitive to their secondary structure. Unfortunately, the Fc also contributes in this region, hampering any simple interpretation. The bands pattern below $250 \mathrm{~nm}$ does not coincide with any well-defined secondary structure motif for either $\mathbf{1}$ or $\mathbf{2}$. In particular, the typical PPI or PPII signatures are absent.[59] This outcome is not surprising because of the short length of both pseudopeptides, however, variable temperature ECD spectra (VT-ECD) were measured in the range between $-35{ }^{\circ} \mathrm{C}$ and $+75^{\circ} \mathrm{C}$ to further highlight the conformational behavior of the smaller compound 1. ECD spectra of organized proteins and peptides are expected to change with temperature, evolving toward unfolded or random coils when the temperature is raised.[60]

The VT-ECD spectra of 1 (Figure 8) show, however, that most UV/ECD bands are unaffected by the temperature change, with the only exception of the positive ECD band centered at $240-245 \mathrm{~nm}$. This band decreased upon heating with a regular trend, as the ECD intensity at $241 \mathrm{~nm}$ varies linearly with the inverse of temperature (Figure S3). The absence of any well-defined secondary structure for the peptide backbone in $\mathbf{1}$ is further confirmed by the fact that ECD bands below $230 \mathrm{~nm}$, associated with the peptide backbone, are not temperature-dependent. 
The only temperature-dependent ECD band around $240 \mathrm{~nm}$ was assigned by computational analysis to a $\pi-\pi^{*}$ transition of the Fc amide (a plot of the transition density is shown as inset in Figure 8). This band seems to be ECD active mainly due to the twist between the substituted Cp ring and the attached amide. Upon raising the temperature, the torsional mode relative to the $\mathrm{Cp}$-amide torsion will increase in flexibility and the planar conformation (with weak or zero ECD) will become more probable. Therefore, the progressive disappearance of the 240-nm ECD band upon temperature increase may be explained with a more extensive conformational averaging. [61]

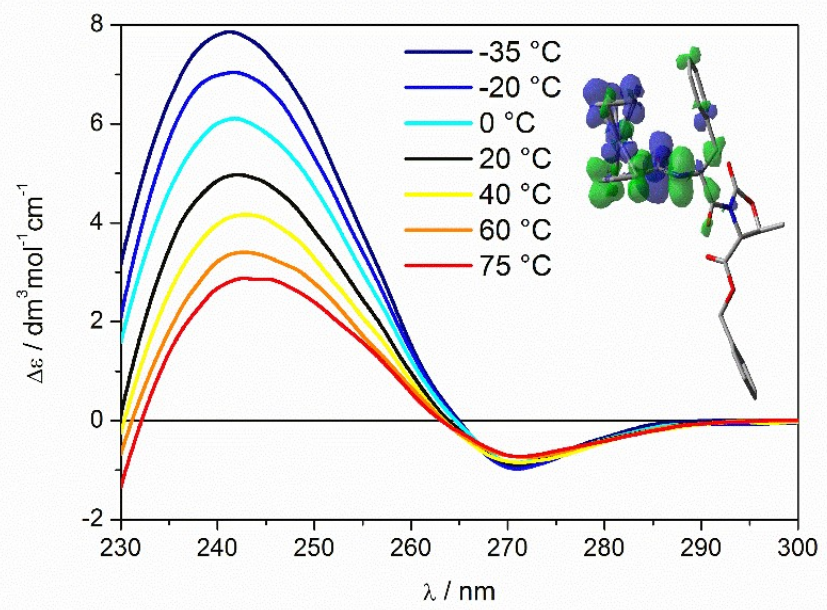

Figure 8. Variable temperature ECD spectra of 1 in acetonitrile solution. Inset: transition density plot for the transition $240 \mathrm{~nm}$ (see text) calculated at TD-M06/TZVP level.

An accurate simulation of $\mathbf{1}$ and $\mathbf{2}$ ECD spectra of is hampered by the complexity and conformational freedom of the system. However, we took advantage of the X-ray structure of $\mathbf{1}$ as starting point for our analysis. The X-ray geometry was relaxed by means of restrained density functional theory (DFT) optimizations, then used as input structure in time-dependent DFT calculations.[62] Upon comparing the calculated and experimental ECD spectrum, we could perform a full transition and orbital analysis (see Supporting Information for details), and assign the main character of the major ECD bands recorded for 1 , including the aforementioned $240-\mathrm{nm}$ band. 

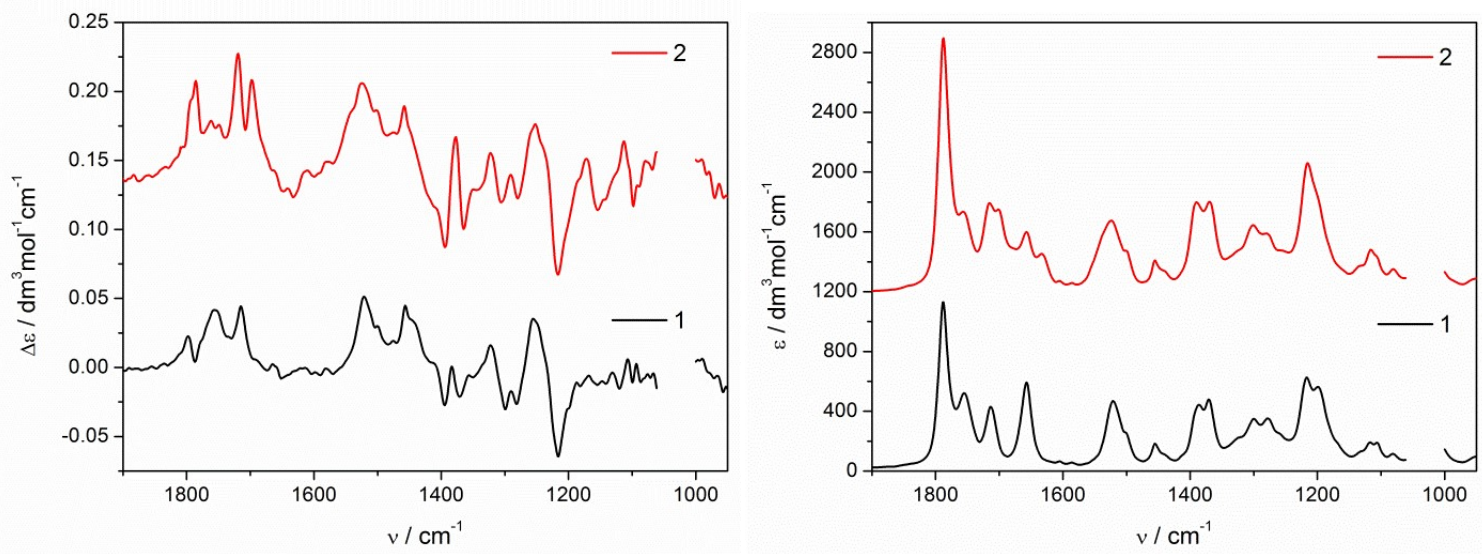

Figure 9. VCD (left) and IR (right) spectra of 1 and $\mathbf{2}$ in acetonitrile- $d^{3}$ solution.

VCD spectra of 1 and 2 recorded in acetonitrile- $d_{3}$ are shown in Figure 9. The spectra are quite similar to each other in the fingerprint region, offering a qualitative proof of the fact that the corresponding molecular portions (FC-L-Phe-D-Oxd) of the two pseudopeptides have a similar conformation in solution. In the amide I/II region, the spectra do not show any distinctive feature of a well-defined secondary structure, including that of PPI or PPII, which needs a regular arrangement of at least three Pro residues to be detectable.[63] It is likely that the oxidation of $\mathrm{Fe}^{2+}$ to $\mathrm{Fe}^{3+}$ may enhance the VCD spectrum especially for the normal modes localized closer to the Fc.[24] Such a study is currently underway.

The results herein reported show that in the ferrocene group forbids the formation of a defined secondary structure, even in the presence of the D-Oxd moiety that induces the formation of folded structures.[64,65] A similar result has been observed by Wang, who reports that Fc-FF changed the conformation of the secondary structures from the flat $\beta$-sheets conformation of phenylalaninephenylalanine (FF) into twisted $\beta$-sheets. $[66,67]$

\section{Conclusions}

In this paper, we report the synthesis and the conformational behavior of two small pseudopeptides containing the ferrocene group at the $\mathrm{N}$-terminal position. After purification, Fc-L-Phe-D-Oxd-OBn 1 appears as bright brown solid that spontaneously forms brown needles. The X-ray diffraction of the crystals shows the presence of strong $\pi$ interactions between the ferrocenyl moiety and the phenyl rings, while no $\mathrm{N}-\mathrm{H} \bullet \bullet \bullet \mathrm{O}=\mathrm{C}$ hydrogen bonds are formed. This result is confirmed by FT-IR and ${ }^{1} \mathrm{H}$ NMR analysis. In contrast, both FT-IR and ${ }^{1} \mathrm{H}$ NMR analysis suggest that Fc-(L-Phe-D-Oxd) $2-\mathrm{OBn} 2$ forms a turn conformation stabilized by intramolecular $\mathrm{N}-\mathrm{H} \bullet \bullet \mathrm{O}=\mathrm{C}$ hydrogen bonds in solution. 
These results are very different from what we previously obtained in the conformational analysis of Boc-(L-Phe-D-Oxd $)_{n}-\mathrm{OBn}(\mathrm{n}=1,2)$ as they both tend to form parallel or antiparallel $\beta$-sheet conformation, thus showing that the ferrocene moiety on these short pseudopeptide chains have a dramatic effect on the structure final conformation. Chiroptical spectroscopies (ECD and VCD) substantially confirmed the absence of a well-defined folded structure. The presence of the Fc moiety is responsible for specific ECD signals, one of which displayed a pronounced temperature dependence and is directly related with the helicity assumed by the Fc core. Solid-state ECD spectra were recorded and rationalized on the basis of the X-ray geometry and quantum-mechanical calculations.

\section{Acknowledgements}

G.P. thanks University of Pisa for PRA_2017_25 grant "Composti di metalli di transizione come possibili agenti antitumorali". M.G. thanks for the support the Polish Ministry of Science and Higher Education ('Mobilnosc Plus' grant no. 1286/MOB/IV/2015/0). All computational calculations were performed at Wroclaw Centre for Networking and Supercomputing (WCSS) in Poland. M.M., N.Z. and C.T. thank the University of Bologna for financial support. C.T. gratefully acknowledges Ministero dell'Università e della Ricerca (PRIN 2015 project 20157WW5EH).

\section{References}

1. Kealy, T. J.; Pauson, P. L. A New Type of Organo-Iron Compound. Nature 1951, 168, 10391040, doi:10.1038/1681039b0.

2. van Staveren, D. R.; Metzler-Nolte, N. Bioorganometallic chemistry of ferrocene. Chem. Rev. 2004, 104, 5931-5985, doi:10.1021/cr0101510.

3. Astruc, D. Why is Ferrocene so Exceptional? Eur. J. Inorg. Chem. 2017, 2017, 6-29, doi:10.1002/ejic.201600983.

4. Lal, B.; Badshah, A.; Altaf, A. A.; Khan, N.; Ullah, S. Miscellaneous applications of ferrocenebased peptides/amides. Appl. Organomet. Chem. 2011, 25, 843-855, doi:10.1002/aoc.1843.

5. Pavan, S.; Berti, F. Short peptides as biosensor transducers. Anal. Bioanal. Chem. 2012, 402, 3055-3070, doi:10.1007/s00216-011-5589-8.

6. Rabti, A.; Raouafi, N.; Merkoçi, A. Bio(Sensing) devices based on ferroceneefunctionalized graphene and carbon nanotubes. Carbon N. Y. 2016, 108, 481-514, doi:10.1016/j.carbon.2016.07.043.

7. Foulds1, N. C.; Lowe, C. R. Immobilization of Glucose Oxidase in Ferrocene-Modified Pyrrole 
Polymers. 1988, 60, 2473-2478.

8. Kulbaba, K.; Manners, I. Polyferrocenylsilanes: Metal-containing polymers for materials science, self-assembly and nanostructure applications. Macromol. Rapid Commun. 2001, 22, 711-724, doi:10.1002/1521-3927(20010701)22:10<711::AID-MARC711>3.0.CO;2-C.

9. Ma, Y.; Dong, W.-F.; Hempenius, M. A.; Ohwald, H.; Vancso, G. J. Redox-controlled molecular permeability of composite-wall microcapsules. Nat. Mater. 2006, 5, 724-729, doi:10.1038/nmat1716.

10. Hudson, R. D. A. Ferrocene polymers: current architectures, syntheses and utility. J. Organomet. Chem. 2001, 637, 47-69.

11. Di Bella, S. Second-order nonlinear optical properties of transition metal complexes. Chem. Soc. Rev. 2001, 30, 355-366, doi:10.1039/B100820J.

12. Sai Sudhir, V.; Phani Kumar, N. Y.; Chandrasekaran, S. Click chemistry inspired synthesis of ferrocene amino acids and other derivatives. Tetrahedron 2010, 66, 1327-1334, doi:10.1016/j.tet.2009.12.011.

13. Wang, R.; Hong, X.; Shan, Z. A novel, convenient access to acylferrocenes: acylation of ferrocene with acyl chlorides in the presence of zinc oxide. Tetrahedron Lett. 2008, 49, 636639, doi:10.1016/j.tetlet.2007.11.119.

14. Dai, L. X.; Tu, T.; You, S. L.; Deng, W. P.; Hou, X. L. Asymmetric Catalysis with Chiral Ferrocene Ligands. Acc. Chem. Res. 2003, 36, 659-667, doi:10.1021/ar020153m.

15. Chowdhury, S.; Schatte, G.; Kraatz, H. B. Rational design of bioorganometallic foldamers: A potential model for parallel ??-helical peptides. Angew. Chemie - Int. Ed. 2006, 45, 68826884, doi:10.1002/anie.200602248.

16. Jaouen, G.; Vessières, A.; Top, S. Ferrocifen type anti cancer drugs. Chem. Soc. Rev. 2015, 44, 8802-8817, doi:10.1039/C5CS00486A.

17. Hillard, E.; Vessières, A.; Thouin, L.; Jaouen, G.; Amatore, C. Ferrocene-mediated protoncoupled electron transfer in a series of ferrocifen-type breast-cancer drug candidates. Angew. Chemie - Int. Ed. 2005, 45, 285-290, doi:10.1002/anie.200502925.

18. Lal, B.; Badshah, A.; Altaf, A. A.; Khan, N.; Ullah, S. Miscellaneous applications of ferrocenebased peptides/amides. Appl. Organomet. Chem. 2011, 25, 843-855, doi:10.1002/aoc.1843.

19. Moriuchi, T.; Hirao, T. Design of Ferrocene-Dipeptide Bioorganometallic Conjugates To Induce Chirality-Organized Structures. Acc. Chem. Res. 1040, 43, 1040-1051, doi:10.1021/ar100022n.

20. Wang, J.; Liu, K.; Yan, L.; Wang, A.; Bai, S.; Yan, X. Trace Solvent as a Predominant Factor to Tune Dipeptide Self-Assembly. ACS Nano 2016, 10, 2138-2143, doi:10.1021/acsnano.5b06567.

21. Abbas, M.; Zou, Q.; Li, S.; Yan, X. Self-Assembled Peptide- and Protein-Based Nanomaterials for Antitumor Photodynamic and Photothermal Therapy. Adv. Mater. 2017, 29, DOI: 10.1002/adma.201605021, doi:10.1002/adma.201605021.

22. Wang, Y.; Huang, R.; Qi, W.; Wu, Z.; Su, R.; He, Z. Kinetically controlled self-assembly of redox-active ferrocene-diphenylalanine: from nanospheres to nanofibers. Nanotechnology 
2013, 24, 465603, doi:10.1088/0957-4484/24/46/465603.

23. Wang, Y.; Huang, R.; Qi, W.; Xie, Y.; Wang, M.; Su, R.; He, Z. Capillary Force-Driven, Hierarchical Co-Assembly of Dandelion-Like Peptide Microstructures. Small 2015, 11, 28932902, doi:10.1002/smll.201403645.

24. Domingos, S. R.; Sanders, H. J.; Hartl, F.; Buma, W. J.; Woutersen, S. Switchable amplification of vibrational circular dichroism as a probe of local chiral structure. Angew. Chemie - Int. Ed. 2014, 53, 14042-14045, doi:10.1002/anie.201407376.

25. Angelici, G.; Falini, G.; Hofmann, H.-J.; Huster, D.; Monari, M.; Tomasini, C. Nanofibers from oxazolidi-2-one containing hybrid foldamers: what is the right molecular size? Chem. - A Eur. J. 2009, 15, doi:10.1002/chem.200900185.

26. Angelici, G.; Falini, G.; Hofmann, H.-J.; Huster, D.; Monari, M.; Tomasini, C. A Fiberlike Peptide Material Stabilized by Single Intermolecular Hydrogen Bonds. Angew. Chemie Int. Ed. 2008, 47, 8075-8078, doi:10.1002/anie.200802587.

27. Berardozzi, R.; Badetti, E.; Carmo dos Santos, N. A.; Wurst, K.; Licini, G.; Pescitelli, G.; Zonta, C.; Di Bari, L. Co( $\langle\mathrm{scp}>\mathrm{ii}</ \mathrm{scp}>$ )-induced giant vibrational CD provides a new design of methods for rapid and sensitive chirality recognition. Chem. Commun. 2016, 52, 8428-8431, doi:10.1039/C6CC04167A.

28. SMART \& SAINT APEX2 and SAINT Programs for Data Reduction. Softw. Ref. Manuals, version 5.051 (Windows NT Version), Bruker Anal. X-ray Instruments Inc. Madison, Wi, 1998.

29. Sheldrick, G. Weblet ImporterProgram for empirical absorption correction of area detector data. SADABS, Progr. Empir. Absorpt. Correct. Univ. Göttingen, Ger. 1996.

30. Altomare, A.; Burla, M. C.; Camalli, M.; Cascarano, G. L.; Giacovazzo, C.; Guagliardi, A.; Moliterni, A. G. G.; Polidori, G.; Spagna, R. \{\it SIR\}97: a new tool for crystal structure determination and refinement. J. Appl. Crystallogr. 1999, 32, 115-119, doi:10.1107/S0021889898007717.

31. Sheldrick, G. Weblet ISHELXTLplus Version 5.1 (Windows NT version)-Structure Determination Packagemporter. SHELXTLplus (Windows NT Version) Struct. Determ. Packag. Version 5.1. Bruker Anal. X-ray Instruments Inc. Madison, WI, USA 1998.

32. Lu, T.; Chen, F. Multiwfn: A multifunctional wavefunction analyzer. J. Comput. Chem. 2012, 33, 580-592, doi:10.1002/jcc.22885.

33. Bruhn, T.; Schaumlöffel, A.; Hemberger, Y.; Pescitelli, G. SpecDis version 1.71, Berlin, Germany, 2017, https://specdis-software.jimdo.com/. SpecDis version 1.71, Berlin, Ger. 2017, https//specdis-software.jimdo.com/, doi:10.1002/chir.22600.

34. Angelici, G.; Falini, G.; Hofmann, H. J.; Huster, D.; Monari, M.; Tomasini, C. Nanofibers from oxazolidi-2-one containing hybrid foldamers: what is the right molecular size? Chem. - A Eur. J. 2009, 15, 8037-8048, doi:10.1002/chem.200900185.

35. Angelici, G.; Castellucci, N.; Contaldi, S.; Falini, G.; Hofmann, H. J.; Monari, M.; Tomasini, C. A network of small molecules connected by cross-linked NH bonds. Cryst. Growth Des. 2010, 10, 244-251, doi:10.1021/cg900874f.

36. Angelici, G.; Castellucci, N.; Falini, G.; Huster, D.; Monari, M.; Tomasini, C. Pseudopeptides 
designed to form supramolecular helixes: The role of the stereogenic centers. Cryst. Growth Des. 2010, 10, 923-929, doi:10.1021/cg9012558.

37. Lucarini, S.; Tomasini, C. Synthesis of oligomers of trans-(4S,5R)-4-carboxybenzyl 5-methyl oxazolidin-2-one: An approach to new foldamers. J. Org. Chem. 2001, 66, 727-732, doi:10.1021/jo005583+.

38. Tomasini, C.; Trigari, V.; Lucarini, S.; Bernardi, F.; Garavelli, M.; Peggion, C.; Formaggio, F.; Toniolo, C. Pseudopeptide foldamers - the homo-oligomers of benzyl (4S,5R)-5-methyl-2oxo-1,3-oxazolidine-4-carboxylate. European J. Org. Chem. 2003, 4, 259-267.

39. Angelici, G.; Luppi, G.; Kaptein, B.; Broxterman, Q. B.; Hofmann, H. J.; Tomasini, C. Synthesis and secondary structure of alternate $\alpha, \beta$-hybrid peptides containing oxazolidin-2-one moieties. European J. Org. Chem. 2007, 2713-2721, doi:10.1002/ejoc. 200700134.

40. Belvisi, L.; Gennari, C.; Mielgo, A.; Potenza, D.; Scolastico, C. Conformational Preferences of Peptides Containing Reverse-Turn Mimetic Bicyclic Lactams: Inverse $\mathrm{Y}$-Turns versus Type-II' $\beta$-Turns - Insights into $\beta$-Hairpin Stability. European J. Org. Chem. 1999, 389-400, doi:DOI: 10.1002/(SICI)1099-0690(199902)1999:2<389::AID-EJOC389>3.0.CO;2-7.

41. Yang, J.; Gellman, S. H. Energetic superiority of two-center hydrogen bonding relative to three- center hydrogen bonding in a model system [11]. J. Am. Chem. Soc. 1998, 120, 90909091, doi:10.1021/ja981604u.

42. Tomasini, C.; Luppi, G.; Monari, M. Oxazolidin-2-one-containing pseudopeptides that fold into beta-bend ribbon spirals. J. Am. Chem. Soc. 2006, 128, 2410-2420.

43. Luppi, G.; Galeazzi, R.; Garavelli, M.; Tomasini, C. Beta-Pseudopeptide foldamers. The homo-oligomers of (4. Org. Biomol. Chem. 2004, 2, 2181-2187.

44. Liu, M.; Zhang, L.; Wang, T. Supramolecular Chirality in Self-Assembled Systems. Chem. Rev. 2015, 115, 7304-7397, doi:10.1021/cr500671p.

45. Barisić, L.; Cakić, M.; Mahmoud, K. a; Liu, Y.; Kraatz, H.-B.; Pritzkow, H.; Kirin, S. I.; MetzlerNolte, N.; Rapić, V. Helically chiral ferrocene peptides containing 1'-aminoferrocene-1carboxylic acid subunits as turn inducers. Chem. A Eur. J. 2006, 12, 4965-80, doi:10.1002/chem.200600156.

46. Barisić, L.; Dropucić, M.; Rapić, V.; Pritzkow, H.; Kirin, S. I.; Metzler-Nolte, N. The first oligopeptide derivative of 1'-aminoferrocene-1-carboxylic acid shows helical chirality with antiparallel strands. Chem. Commun. 2004, 2004-2005, doi:10.1039/b407771g.

47. Barišić, L.; Kovačević, M.; Mamić, M.; Kodrin, I.; Mihalić, Z.; Rapić, V. Synthesis and Conformational Analysis of Methyl N-Alanyl-1'-aminoferrocene-1-carboxylate. Eur. J. Inorg. Chem. 2012, 2012, 1810-1822, doi:10.1002/ejic.201101270.

48. Djaković, S.; Kodrin, I.; Smrečki, V.; Novak, P.; Mihalić, Z.; Žiher, D.; Lapić, J.; Rapić, V. 1'Acetylferrocene amino acid esters and amides. A simple model for parallel $\beta$-helical peptides. Tetrahedron 2014, 70, 2330-2342, doi:10.1016/j.tet.2014.02.047.

49. Heinze, K.; Beckmann, M. Conformational analysis of chiral ferrocene-peptides. Eur. J. Inorg. Chem. 2005, 2, 3450-3457, doi:10.1002/ejic.200500268.

50. Kovač, V.; Čakić Semencic, M.; Kodrin, I.; Roca, S.; Rapić, V. Ferrocene-dipeptide conjugates 
derived from aminoferrocene and 1-acetyl-1'-aminoferrocene: Synthesis and conformational studies. Tetrahedron 2013, 69, 10497-10506, doi:10.1016/j.tet.2013.09.048.

51. Lapić, J.; Siebler, D.; Heinze, K.; Rapic, V. Conformational analysis of heteroannularly substituted ferrocene oligoamides. Eur. J. Inorg. Chem. 2007, 2014-2024, doi:10.1002/ejic.200601230.

52. Mojca, C.; Siebler, D.; Heinze, K.; Rapic, V. Bis- and Trisamides Derived From 1 \# Aminoferrocene-1-carboxylic Acid and \#-Amino Acids : Synthesis and Conformational Analysis Bis- and Trisamides Derived From 1 ' -Aminoferrocene-1-carboxylic Acid and $r$ Amino Acids : Synthesis and Conformational Anal. 2009, 2028-2037, doi:10.1021/om801163s.

53. Moriuchi, T.; Nomoto, A.; Yoshida, K.; Ogawa, A.; Hirao, T. Chirality organization of ferrocenes bearing podand dipeptide chains: Synthesis and structural characterization. $J$. Am. Chem. Soc. 2001, 123, 68-75, doi:10.1021/ja002869n.

54. Siebler, D.; Mojca, C.; Rapić, V. Spectroscopic and Theoretical Study of Asymmetric 1, $1^{\prime}$ Diaminoferrocene Conjugates of r-Amino Acids `akic. Organometallics 2008, 27, 14471453.

55. Wang, Y.; Qi, W.; Huang, R.; Yang, X.; Wang, M.; Su, R.; He, Z. Rational Design of Chiral Nanostructures from Self-Assembly of a Ferrocene-Modified Dipeptide. J. Am. Chem. Soc. 2015, 137, 7869-7880, doi:10.1021/jacs.5b03925.

56. Keiderling, T. A. Protein and peptide secondary structure and conformational determination with vibrational circular dichroism. Curr. Opin. Chem. Biol. 2002, 6, 682-688, doi:10.1016/S1367-5931(02)00369-1.

57. Knapp Krisztina, Górecki Marcin, Frelek Jadwiga, Luboradzki Roman, Hollósi Miklós, Majerz Suzsa, V. E. Comprehensive Chiroptical Study of Proline-Containing Diamide Compounds. Chirality 2014, 26, 228-242, doi:10.1002/chir.22305.

58. Cecilia Noguez, F. H. Ab Initio Electronic Circular Dichroism of Fullerenes, Single-Walled Carbon Nanotubes, and Ligand-Protected Metal Nanoparticles. Chirality 2014, 26, 553-562, doi:10.1002/chir.

59. Bochicchio, B.; Tamburro, A. M. Polyproline II structure in proteins: Identification by chiroptical spectroscopies, stability, and functions. Chirality 2002, 14, 782-792, doi:10.1002/chir.10153.

60. Greenfield, N. Using circular dichroism spectra to estimate protein secondary structure. Nat Protoc. 2007, 1, 2876-2890, doi:10.1038/nprot.2006.202.Using.

61. Pescitelli, G.; Di Bari, L.; Berova, N. Conformational aspects in the studies of organic compounds by electronic circular dichroism. Chem. Soc. Rev. 2011, 40, 4603-4625, doi:10.1039/c1cs15036g.

62. Srebro-hooper, M.; Autschbach, J. Calculating Natural Optical Activity of Molecules from First Principles. 2016.

63. Dukor, R. K.; Keiderling, T. A. Reassessment of the random coil conformation: Vibrational CD study of proline oligopeptides and related polypeptides. Biopolymers 1991, 31, 1747-1761, 
doi:10.1002/bip.360311409.

64. Zanna, N.; Focaroli, S.; Merlettini, A.; Gentilucci, L.; Teti, G.; Falconi, M.; Tomasini, C. Thixotropic Peptide-Based Physical Hydrogels Applied to Three-Dimensional Cell Culture. ACS Omega 2017, 2, 2374-2381, doi:10.1021/acsomega.7b00322.

65. Milli, L.; Zanna, N.; Merlettini, A.; Di Giosia, M.; Calvaresi, M.; Focarete, M. L.; Tomasini, C. Pseudopeptide-Based Hydrogels Trapping Methylene Blue and Eosin Y. Chem. - A Eur. J. 2016, 12106-12112, doi:10.1002/chem.201601861.

66. Wang, Z. J.; Zhu, C. N.; Hong, W.; Wu, Z. L.; Zheng, Q. Programmed planar-to-helical shape transformations of composite hydrogels with bioinspired layered fibrous structures. J. Mater. Chem. B 2016, doi:10.1039/C6TB02178F.

67. Liu, X.; Fei, J.; Wang, A.; Cui, W.; Zhu, P.; Li, J. Transformation of Dipeptide-Based Organogels into Chiral Crystals by Cryogenic Treatment. Angew. Chemie Int. Ed. 2017, 56, 2660-2663, doi:10.1002/anie.201612024. 